\title{
Fixed Point Theorems for the Maps Satisfying Contractive Condition of Integral Type in Metric Spaces
}

\author{
Avinash Chandra Upadhyaya \\ Department of Mathematics \\ Deenbandhu ChhotuRam \\ University of Science and Technology \\ Murthal-131039, \\ Haryana, India.
}

\begin{abstract}
In this paper, we prove fixed point theorems for the maps satisfying contractive condition of integral type using occasionally weakly compatible maps along with property (E.A.).
\end{abstract}

\section{Keywords}

Weakly compatible maps, occasionally weakly compatible maps, property (E.A. ) and Common property (E.A.).

Subject classification: (2001) AMS 47 H10, 54 H25.

\section{INTRODUCTION}

There has been a considerable interest to study common fixed point for a pair of mappings satisfying contractive conditions in metric spaces for the last quarter of the 20th century. Several interesting and elegant results were obtained in this direction by various authors. It was the turning point in the "fixed point arena" when the notion of commutativity was used by Jungck [12] to obtain a generalization of Banach's fixed point theorem for a pair of mappings. This theorem has had many applications, but suffers from one drawback-the definition requires that $\mathrm{T}$ be continuous throughout $\mathrm{X}$. This result was further generalized and extended in various ways by many authors. On the other hand, Sessa [20] coined the notion of weak commutativity and proved a common fixed point theorem for these mappings. In 1996, Jungck [12] introduce the notion of weakly compatible mappings for set valued non-continuous functions.

Aamri and El Moutawakil [1] generalized the concept of non compatibility in metric spaces by defining the notion property (E.A.) and proved common fixed point theorems under strict contractive conditions.

It was pointed out in [1] that property ( E. A.) buys containment of ranges without any continuity requirements besides minimizes the commutativity conditions of the maps to the commutativity at their points of coincidence. Moreover, property ( E. A.) allows replacing the completeness requirement of the space with a more natural condition of closeness of the range. A major benefit of property (E.A.) is that it ensures convergence of desired sequences without completeness.

In 2008, Al-Thagafi and Naseer Shahzad [2] introduced the concept of occasionally weakly compatible mappings.

\section{Definition 1.1.}

Let $\mathrm{A}$ and $\mathrm{T}$ be self-maps of a set $\mathrm{X}$. If $\mathrm{Ax}=\mathrm{Tx}=\mathrm{w}$ (say), $\mathrm{w} \in$ $\mathrm{X}$, for some $\mathrm{x}$ in $\mathrm{X}$, then $\mathrm{x}$ is called a coincidence point of $\mathrm{A}$ and $\mathrm{T}$. The set of coincidence points of $\mathrm{A}$ and $\mathrm{T}$ in $\mathrm{X}$ is denoted by $\mathrm{C}(\mathrm{A}, \mathrm{T})$ and $\mathrm{w}$ is called a point of coincidence of
A and $\mathrm{T}$.

Definition 1.2

The pair $(\mathrm{A}, \mathrm{T})$ is said to

(i) be compatible [11] if $\lim _{n \rightarrow \infty} \mathrm{d}\left(\mathrm{ATx}_{\mathrm{n}}, \mathrm{TAx}_{\mathrm{n}}\right)=0$, whenever $\left\{x_{n}\right\}$ is a sequence in $X$ such that $\lim _{n \rightarrow \infty} A x_{n}=\lim _{n \rightarrow \infty} \mathrm{Tx}_{\mathrm{n}}=\mathrm{t}$, for some $\mathrm{t}$ in $\mathrm{X}$.

(ii) be noncompatible if there is at least one sequence $\left\{x_{n}\right\}$ in $X$ such that $\lim _{n \rightarrow \infty} A x_{n}=$ $\lim _{n \rightarrow \infty} \operatorname{Tx}_{\mathrm{n}}=\mathrm{t}$, for some $\mathrm{t}$ in $\mathrm{X}$, but $\lim _{n \rightarrow \infty} \mathrm{d}\left(\mathrm{ATx}_{\mathrm{n}}\right.$, $\mathrm{TAx}_{\mathrm{n}}$ ) is either non-zero or non-existent.

(iii) satisfy property (E.A.) [1] if there exists a sequence $\left\{x_{n}\right\}$ in $X$ such that $\lim _{n \rightarrow \infty} A x_{n}=$ $\lim _{n \rightarrow \infty} \operatorname{Tx}_{\mathrm{n}}=\mathrm{t}$, for some $\mathrm{t}$ in $\mathrm{X}$.

(iv) be weakly compatible [13] if $\mathrm{TAx}=\mathrm{ATx}$ whenever $A x=T x, x \in X$.

(v) be occasionally weakly compatible (owc) [2] if $\mathrm{TAx}=\mathrm{AT} \mathrm{x}$ for some $\mathrm{x} \in \mathrm{C}(\mathrm{A}, \mathrm{T})$.

Al-Thagafi and Naseer Shahzad [2] shown that occasionally weakly is weakly compatible but converse is not true.

Example 1.3.[2] Let $R$ be the usual metric space. Define $S, T$ $: \mathrm{R} \rightarrow \mathrm{R}$ by $\mathrm{Sx}=2 \mathrm{x}$ and $\mathrm{Tx}=\mathrm{x}^{2}$ for all $\mathrm{x} \in \mathrm{R}$. Then $\mathrm{Sx}=\mathrm{Tx}$ for $\mathrm{x}=0,2$ but ST0 $=\mathrm{TS} 0$, and ST2 $\neq \mathrm{TS} 2$. The pair $(\mathrm{S}, \mathrm{T})$ is occasionally weakly compatible but not weakly compatible.

Remark 1.4. (i) Every pair of non compatible self maps of a metric space (X, d) satisfies property( E.A.), but converse need not be true [5].

1. (ii) weak compatibility and property (E.A.) are independent of each other [18].

2. (iii) every compatible pair is weakly compatible but its converse need not be true [13].

3. (iv) every weakly compatible pair is occasionally weakly compatible but its converse need not

4. be true [3].

5. occasionally weak compatibility and property (E.A.) are independent of each other [14].

Definition 1.5.[16] Let $(X, d)$ be a metric space and A, B, S and $\mathrm{T}$ be four self maps on $\mathrm{X}$. The pairs $(\mathrm{A}, \mathrm{S})$ and $(\mathrm{B}, \mathrm{T})$ are said to satisfy common property (E.A.) if there exist two sequences $\left\{x_{n}\right\}$ and $\left\{y_{n}\right\}$ in $X$ such that $\lim _{n \rightarrow \infty} A x_{n}=\lim _{n \rightarrow \infty} S x_{n}=$ $\lim _{n \rightarrow \infty} B y_{n}=\lim _{n \rightarrow \infty} \mathrm{Ty}_{\mathrm{n}}=\mathrm{t}$, for some $\mathrm{t}$ in $\mathrm{X}$. 


\section{MAIN RESULTS}

A study of contractive conditions of integral type was initiated in 2002 by Branciari [8] who gave the version of the Banach contraction principle that could be extended to more general contractive conditions. (We denote by $\mathbb{R}+$ the set of all nonnegative reals; we say that a function $\mathrm{f}: \mathbb{R}+\rightarrow \mathbb{R}$ is Lebesgue locally integrable if it has a finite integral on every bounded interval in $\mathbb{R}+$.)

Branciari [8] established the following fixed theorem.

\section{Theorem 1.}

Let $(X, d)$ be a complete metric space, $c \in(0,1)$, and let $T: X$ $\rightarrow \mathrm{X}$ be a mapping such that for each $\mathrm{x}, \mathrm{y} \in \mathrm{X}$,

$$
\int_{0}^{d(T x, T y)} \phi(s) d s \leq \mathrm{c} \int_{0}^{d(x, y)} \phi(s) d s
$$

where $:[0, \infty) \rightarrow[0, \infty)$ is a Lebesgue integrable mapping which is summable on each compact subset of $[0, \infty)$ and such that for all $\epsilon>0, \int_{0}^{\epsilon} \phi(s) d s>0$.

Then, $\mathrm{T}$ has a unique fixed point $\mathrm{a} \in \mathrm{X}$ such that for each $\mathrm{x} \in$ $\mathrm{X}, \operatorname{Tn} \mathrm{x} \rightarrow$ a as $\mathrm{n} \rightarrow \infty$.

Clearly, Theorem 1 yields the Banach contraction principle ( $\operatorname{set} \phi(s)=1$ for $s \in \mathbb{R}+$ ). Subsequently, Theorem 1 was generalized by Rhoades [19] by substituting the term $\mathrm{m}(\mathrm{x}, \mathrm{y})$ for $\mathrm{d}(\mathrm{x}, \mathrm{y})$ in $(1)$, where

$$
M(x, y)=\max \left\{d(x, y), d(x, T x), d(y, T y), \frac{(d(x, T y)+d(y, T x))}{2}\right.
$$

Later on, the authors in ([4], [9], [23]) established fixed point theorems involving more general contractive conditions. Suzuki [21] showed that Meir-Keeler contractions of integral type are still Meir-Keeler contractions and so proved that Theorem 1 of Branciari is a particular case of the Meir-Keeler fixed point theorem [17].

In 2010, Calogero Vetro [22] proved the following theorem for weakly compatible mappings:

\section{Theorem 2.}

Let $(\mathrm{X}, \mathrm{d})$ be a metric space and let $\mathrm{A}, \mathrm{B}, \mathrm{S}$ and $\mathrm{T}$ be selfmappings of $\mathrm{X}$ with $\mathrm{S}(\mathrm{X}) \subseteq \mathrm{B}(\mathrm{X})$ and $\mathrm{T}(\mathrm{X}) \subseteq \mathrm{A}(\mathrm{X})$ satisfying

$\int_{0}^{d(S x, T y)} \phi(s) d s \leq \alpha \int_{0}^{m(x, y)} \phi(s) d s+\beta \int_{0}^{M(x, y)} \phi(s) d s$, where

$\mathrm{m}(\mathrm{x}, \mathrm{y})=\mathrm{d}(\mathrm{By}, \mathrm{Ty}) \frac{1+d(A x, S x)}{1+d(A x, B y)}$

and

$\mathrm{M}(\mathrm{x}, \mathrm{y})=\max \{\mathrm{d}(\mathrm{Ax}, \mathrm{By}), \mathrm{d}(\mathrm{Ax}, \mathrm{Sx}), \mathrm{d}(\mathrm{By}, \mathrm{Ty})\}$,

for all $\mathrm{x}, \mathrm{y} \in \mathrm{X}$, where $\alpha>0, \beta>0, \alpha+\beta<1$ and $\phi:[0, \infty)$ $\rightarrow[0, \infty)$ is a Lebesgue integrable mapping on each compact subset of $[0, \infty)$ and such that for all $\epsilon>0, \int_{0}^{\epsilon} \phi(s) d s>0$.

Suppose that one of $\mathrm{A}(\mathrm{X}), \mathrm{B}(\mathrm{X}), \mathrm{S}(\mathrm{X})$ and $\mathrm{T}(\mathrm{X})$ is a complete subset of $X$ and the pairs $\{A, S\}$ and $\{B, T\}$ are weakly compatible.

Then A, B, S and T have a unique common fixed point in $\mathrm{X}$.

In this paper, we prove the existence of common fixed points for pairs of occasionally weakly compatible self maps satisfying property (E.A.)/common property (E.A.) . Our result is more generalized than Theorem 2 as it relaxes one of set inclusions.
Now we come to our main results.

Proposition 2.1. Let $\mathrm{A}, \mathrm{B}, \mathrm{S}$ and $\mathrm{T}$ be four self maps of a metric space $(X, d)$ satisfying the inequality

$\int_{0}^{M(x, y)} \phi(s) d s$, where

$$
\int_{0}^{d(S x, T y)} \phi(s) d s \leq \alpha \int_{0}^{m(x, y)} \phi(s) d s+\beta
$$

$$
\mathrm{m}(\mathrm{x}, \mathrm{y})=\mathrm{d}(\mathrm{By}, \mathrm{Ty}) \frac{1+d(A x, S x)}{1+d(A x, B y)}
$$

and

$$
\mathrm{M}(\mathrm{x}, \mathrm{y})=\max \{\mathrm{d}(\mathrm{Ax}, \mathrm{By}), \mathrm{d}(\mathrm{Ax}, \mathrm{Sx}), \mathrm{d}(\mathrm{By}, \mathrm{Ty})\},
$$

for all $\mathrm{x}, \mathrm{y} \in \mathrm{X}$, where $\alpha>0, \beta>0, \alpha+\beta<1$ and $\phi:[0, \infty)$ $\rightarrow[0, \infty)$ is a Lebesgue integrable mapping on each compact subset of $[0, \infty)$ and such that for all $\epsilon>0, \int_{0}^{\epsilon} \phi(s) d s>0$.

Suppose that either

(i) $\quad \mathrm{S}(\mathrm{X}) \subseteq \mathrm{B}(\mathrm{X})$, the pair $(\mathrm{A}, \mathrm{S})$ satisfies property (E. A.) and $A(X)$ is a closed subspace of $X$;

(ii) $\quad \mathrm{T}(\mathrm{X}) \subseteq \mathrm{A}(\mathrm{X})$, the pair $(\mathrm{B}, \mathrm{T})$ satisfies property (E. A.) and $\mathrm{B}(\mathrm{X})$ is a closed subspace of $\mathrm{X}$; holds.

Then $\mathrm{C}(\mathrm{A}, \mathrm{S}) \neq \varnothing$ and $\mathrm{C}(\mathrm{B}, \mathrm{T}) \neq \varnothing$.

Proof: Suppose (i) holds. Since the pair (A,S) satisfies property (E.A.), then there exists a sequence $\{x n\}$ in $X$ such that $\lim _{n \rightarrow \infty} A x n=\lim _{n \rightarrow \infty} S x n=z$ for some $z \in X$.

Since $S(X) \subset B(X)$, there exists a sequence $\{y n\}$ in $X$ such that $\operatorname{Sxn}=$ Byn . Hence $\lim _{n \rightarrow \infty} \operatorname{Byn}=\mathrm{z}$.

First we claim that $\lim _{n \rightarrow \infty}$ Tyn $=z$, for this purpose, put $x=x n$, and $\mathrm{y}=\mathrm{yn}$ in (2.1), we have

$\int_{0}^{d\left(S x_{n}, T y_{n}\right)} \phi(s) d s \leq \alpha \int_{0}^{m\left(x_{n}, y_{n}\right)} \phi(s) d s+\beta$

$\int_{0}^{M\left(x_{n}, y_{n}\right)} \phi(s) d s$, where

$\mathrm{m}\left(\mathrm{x}_{\mathrm{n}}, \mathrm{y}_{\mathrm{n}}\right)=\mathrm{d}\left(\mathrm{By}_{\mathrm{n}}, \mathrm{Ty}_{\mathrm{n}}\right) \frac{1+d\left(A x_{n}, S x_{n}\right)}{1+d\left(A x_{n}, B y_{n}\right)}$ and

$\mathrm{M}\left(\mathrm{x}_{\mathrm{n}}, \mathrm{y}_{\mathrm{n}}\right)=\max \left\{\mathrm{d}\left(\mathrm{Ax}_{\mathrm{n}}, \mathrm{By_{n }}\right), \mathrm{d}\left(\mathrm{Ax}_{\mathrm{n}}, \mathrm{Sx_{n }}\right), \mathrm{d}\left(\mathrm{By}_{\mathrm{n}}, \mathrm{Ty}_{\mathrm{n}}\right)\right\}$

On taking limit superior in above inequality, we have, $\lim _{n \rightarrow \infty}$ $\mathrm{Ty}_{\mathrm{n}}=\mathrm{z}$.

Since $A(X)$ is a closed subspace of $X$, therefore $z \in A(X)$ and this implies $\mathrm{z}=\mathrm{Av}$ for some $\mathrm{v} \in \mathrm{X}$.

If $\mathrm{Sv} \neq \mathrm{z}$, then on putting $\mathrm{x}=\mathrm{v}$ and $\mathrm{y}=\mathrm{y}_{\mathrm{n}}$ in (2.1), we have

$$
\begin{aligned}
& \int_{0}^{d\left(S v, T y_{n}\right)} \phi(s) d s \leq \alpha \int_{0}^{m\left(v, y_{n}\right)} \phi(s) d s+\beta \\
& \int_{0}^{M\left(v, y_{n}\right)} \phi(s) d s, \text { where } \\
& \mathrm{m}\left(\mathrm{v}, \mathrm{y}_{\mathrm{n}}\right)=\mathrm{d}\left(\mathrm{By}_{\mathrm{n}}, \mathrm{Ty}_{\mathrm{n}}\right) \frac{1+d(A v, S v)}{1+d\left(A v, B y_{n}\right)} \text { and } \\
& \mathrm{M}\left(\mathrm{v}, \mathrm{y}_{\mathrm{n}}\right)=\max \left\{\mathrm{d}\left(\mathrm{Av}, \mathrm{By_{ \textrm {n } }}\right), \mathrm{d}(\mathrm{Av}, \mathrm{Sv}), \mathrm{d}\left(\mathrm{By}_{\mathrm{n}}, \mathrm{Ty}_{\mathrm{n}}\right)\right\},
\end{aligned}
$$

On letting $\mathrm{n} \rightarrow \infty$, we have

$\lim _{n \rightarrow \infty} \mathrm{m}\left(\mathrm{v}, \mathrm{y}_{\mathrm{n}}\right)=0$ and $\lim _{n \rightarrow \infty} \mathrm{M}\left(\mathrm{v}, \mathrm{y}_{\mathrm{n}}\right)=\lim _{n \rightarrow \infty} \max \{0$, $\mathrm{d}(\mathrm{z}, \mathrm{Sv}), 0\}=\mathrm{d}(\mathrm{z}, \mathrm{Sv})$.

Therefore, we have $\mathrm{Sv}=\mathrm{z}=\mathrm{Av}$.

Hence, $C(\mathrm{~A}, \mathrm{~S}) \neq \varnothing$. 
Now, since $S(X) \subseteq B(X)$ and $z \in S(X)$, there exists $u \in X$ such that $\mathrm{z}=\mathrm{Bu}$.

If $\mathrm{Tu} \neq \mathrm{z}$, then on putting $\mathrm{x}=\mathrm{v}$ and $\mathrm{y}=\mathrm{u}$ in (2.1), we have $\int_{0}^{d(S v, T u)} \phi(s) d s \leq \alpha \int_{0}^{m(v, u)} \phi(s) d s+\beta \int_{0}^{M(v, u)} \phi(s) d s$, where

$\mathrm{m}(\mathrm{v}, \mathrm{u})=\mathrm{d}(\mathrm{Bu}, \mathrm{Tu}) \frac{1+d(A v, S v)}{1+d(A v, B u)} \quad$ and

$\mathrm{M}(\mathrm{v}, \mathrm{u})=\max \{\mathrm{d}(\mathrm{Av}, \mathrm{Bu}), \mathrm{d}(\mathrm{Av}, \mathrm{Sv}), \mathrm{d}(\mathrm{Bu}, \mathrm{Tu})\}=\max \{0,0$

$\mathrm{d}(\mathrm{z}, \mathrm{Tu})\}=\mathrm{d}(\mathrm{z}, \mathrm{Tu})$.

Therefore, we have $\mathrm{Bu}=\mathrm{Tu}=\mathrm{z}$.

Hence, $C(B, T) \neq \varnothing$.

Similarly, the assertion of the theorem holds under assumption (ii).

Hence, Proposition 2.1 follows.

Theorem 2.2. In addition to hypothesis of proposition (2.1) on $\mathrm{A}, \mathrm{B}, \mathrm{S}$ and $\mathrm{T}$, if both the pairs $(\mathrm{A}, \mathrm{S})$ and $(\mathrm{B}, \mathrm{T})$ are owc on $\mathrm{X}$, then the maps $\mathrm{A}, \mathrm{B}, \mathrm{S}$ and $\mathrm{T}$ have a unique common fixed point in $\mathrm{X}$.

Proof. By proposition $(2.1), C(A, S) \neq \emptyset$, and $C(B, T) \neq \emptyset$. Since the pair $(B, T)$ is owc, therefore there exists $u_{1} \in C(B, T)$ such that $\mathrm{Tu}_{1}=\mathrm{Bu}_{1}=\mathrm{z}_{1}$ (say) and $\mathrm{TBu}_{1}=\mathrm{BTu} \mathrm{u}_{1}$, therefore $\mathrm{Tz}_{1}$ $=B z_{1}=z_{2}$ (say). Since the pair $(A, S)$ is owc, therefore there exists $\mathrm{v}_{1} \in \mathrm{C}(\mathrm{A}, \mathrm{S})$ such that $\mathrm{Sv}_{1}=A \mathrm{v}_{1}=\mathrm{w}$ (say) and $\mathrm{SAv}_{1}=$ $A \mathrm{~Sv}_{1}$, i.e., $\mathrm{Sw}=\mathrm{Aw}=\mathrm{w}_{1}$ (say).

Next we claim that $z_{2}=w_{1}$.

If $z_{2} \neq w_{1}$, then form (2.1), we have

$\int_{0}^{d\left(S w, T z_{1}\right)} \phi(s) d s \leq \alpha \int_{0}^{m\left(w, z_{1}\right)} \phi(s) d s+\beta \int_{0}^{M\left(w, z_{1}\right)} \phi(s) d s$, where

$\mathrm{m}\left(\mathrm{w}, \mathrm{z}_{1}\right)=\mathrm{d}\left(\mathrm{Bz}_{1}, \mathrm{Tz}_{1}\right) \frac{1+d(A w, S w)}{1+d\left(A w, B z_{1}\right)}$ and

$\mathrm{M}\left(\mathrm{w}, \mathrm{z}_{1}\right)=\max \left\{\mathrm{d}\left(\mathrm{Aw}, \mathrm{Bz}_{1}\right), \mathrm{d}(\mathrm{Aw}, \mathrm{Sw}), \mathrm{d}\left(\mathrm{Bz}_{1}, \mathrm{Tz}_{1}\right)\right\}$.

Therefore we have $\mathrm{z}_{2}=\mathrm{w}_{1}$.

Therefore, we have $\mathrm{Tz}_{1}=\mathrm{Bz_{1 }}=\mathrm{w}_{1}$. Next we show that $\mathrm{z}_{1}=$ $\mathrm{w}_{1}$,

If $z_{1} \neq w_{1}$, then form (2.1.), we have

$\int_{0}^{d\left(s w, T u_{1}\right)} \phi(s) d s \leq \alpha \int_{0}^{m\left(w, u_{1}\right)} \phi(s) d s+\beta$

$\int_{0}^{M\left(w, u_{1}\right)} \phi(s) d s$, where

$\mathrm{m}\left(\mathrm{w}, \mathrm{u}_{1}\right)=\mathrm{d}\left(\mathrm{Bu}_{1}, \mathrm{Tu}_{1}\right) \frac{1+d(A w, S w)}{1+d\left(A w, B u_{1}\right)}$ and

$\mathrm{M}\left(\mathrm{w}, \mathrm{u}_{1}\right)=\max \left\{\mathrm{d}\left(\mathrm{Aw}, \mathrm{Bu}_{1}\right), \mathrm{d}(\mathrm{Aw}, \mathrm{Sw}), \mathrm{d}\left(\mathrm{Bu}_{1}, \mathrm{Tu}_{1}\right)\right\}$, imply $\mathrm{z}_{1}=\mathrm{w}_{1}$.

Thus $\mathrm{Tz}_{1}=\mathrm{Bz}_{1}=\mathrm{z}_{1}$ and $\mathrm{Sw}=\mathrm{Aw}=\mathrm{z}_{1}$.

Next we claim that $w=z_{1}$. If $w \neq z_{1}$, then from (2.1)., we have

$\int_{0}^{d\left(w, z_{1}\right)} \phi(s) d s=\int_{0}^{d\left(S v_{1}, T z_{1}\right)} \phi(s) d s \leq \alpha \int_{0}^{m\left(v_{1}, z_{1}\right)} \phi(s) d s+$ $\beta \int_{0}^{M\left(v_{1}, z_{1}\right)} \phi(s) d s$, where

$\mathrm{m}\left(\mathrm{v}_{1}, \mathrm{z}_{1}\right)=\mathrm{d}\left(\mathrm{Bz}_{1}, \mathrm{Tz}_{1}\right) \frac{1+d\left(A v_{1}, S v_{1}\right)}{1+d\left(A v_{1}, B z_{1}\right)}$ and

$\mathrm{M}\left(\mathrm{v}_{1}, \mathrm{z}_{1}\right)=\max \left\{\mathrm{d}\left(\mathrm{Av}_{1}, \mathrm{Bz}_{1}\right), \mathrm{d}\left(\mathrm{Av}_{1}, \mathrm{~Sv}_{1}\right), \mathrm{d}\left(\mathrm{Bz}_{1}, \mathrm{Tz}_{1}\right)\right\}$,imply $\mathrm{w}=\mathrm{z}_{1}$. Hence we have $\quad \mathrm{Bz}_{1}=\mathrm{Tz}_{1}=\mathrm{z}_{1}$.
Therefore, we obtain $\mathrm{Az}_{1}=\mathrm{Tz}_{1}=\mathrm{Bz}_{1}=\mathrm{Sz}_{1}=\mathrm{z}_{1}$.

Uniqueness follows easily from the inequality (2.1).

Remark 2.3. In Theorem, Calogero Vetro[22] used $T(X) \subseteq$ $\mathrm{A}(\mathrm{X})$ and $\mathrm{S}(\mathrm{X}) \subseteq \mathrm{B}(\mathrm{X})$, where as in Theorem 2.2, we relaxed one of these set inclusions.

Example 2.4. Let $X=\left[\frac{1}{3}, 1\right)$ with the usual metric. We define mappings $\mathrm{A}, \mathrm{B}, \mathrm{S}$ and $\mathrm{T}$ on $\mathrm{X}$ by

$$
\begin{gathered}
\mathrm{A}(\mathrm{x})=\left\{\begin{array}{ll}
\frac{1}{2} & \text { if } \frac{1}{3} \leq x<\frac{2}{3} \\
1-\frac{1}{2} x & \text { if } \frac{2}{3} \leq x<1,
\end{array} \quad \mathrm{~B}(\mathrm{x})=\right. \\
\left\{\begin{array}{l}
\frac{1}{2} \quad \text { if } \frac{1}{3} \leq x<\frac{2}{3} \\
\frac{1}{3}+\frac{1}{2} x \quad \text { if } \frac{2}{3} \leq x<1,
\end{array}\right.
\end{gathered}
$$

$$
\mathrm{S}(\mathrm{x})=\mathrm{T}(\mathrm{x})= \begin{cases}\frac{3}{4} & \text { if } \frac{1}{3} \leq x<\frac{2}{3} \\ \frac{2}{3} & \text { if } \frac{2}{3} \leq x<1,\end{cases}
$$

We observe that $S(X) \subset B(X), A(X)$ is a closed subset of $X$; and neither $\mathrm{T}(\mathrm{X}) \subseteq \mathrm{A}(\mathrm{X})$ nor $\mathrm{A}(\mathrm{X}) \subseteq \mathrm{T}(\mathrm{X})$. The selfmaps $\mathrm{A}$, $\mathrm{B}, \mathrm{S}$ and T satisfy the inequality (2.1.1) with $\phi(s)=1$ and $\alpha=$ $\frac{1}{3}, \beta=\frac{1}{2}$. The sequence $\left\{\mathrm{x}_{\mathrm{n}}\right\}, \mathrm{x}_{\mathrm{n}}=\frac{2}{3}+\frac{1}{n+4}, \mathrm{n}=1,2,3 \ldots$ is in $X$ such that $\lim _{n \rightarrow \infty} A x_{n}=\lim _{n \rightarrow \infty} S x_{n}=\frac{2}{3}$, so that the pair $(S, A)$ satisfies property (E.A.). But the pair (S, A) is not compatible for

$\lim _{n \rightarrow \infty} \mathrm{d}\left(\operatorname{Sax}_{\mathrm{n}}, \mathrm{ASx}_{\mathrm{n}}\right)=\frac{1}{12} \neq 0$. Clearly, the pairs $(\mathrm{A}, \mathrm{S})$ and $(\mathrm{B}$, T) are owc. Hence, the selfmaps A, B, S and T satisfy all the conditions of Theorem 2.2 and $\frac{2}{3}$ is the unique common fixed point of $\mathrm{A}, \mathrm{B}, \mathrm{S}$ and $\mathrm{T}$.

In the following, we prove the existence of common fixed points of $\mathrm{A}, \mathrm{B}, \mathrm{S}$ and $\mathrm{T}$ by imposing the condition common property (E.A.) and relaxing the two containments $\mathrm{T}(\mathrm{X}) \subseteq$ $\mathrm{A}(\mathrm{X})$ and $\mathrm{S}(\mathrm{X}) \subseteq \mathrm{B}(\mathrm{X})$.

Proposition 2.5. Let A, B, S and T be four self maps of a metric space $(\mathrm{X}, \mathrm{d})$ satisfying the inequality (2.1) of Proposition 2.1. Suppose that $(A, S)$ and $(B, T)$ satisfy a common property (E.A.); and $\mathrm{B}(\mathrm{X})$ and $\mathrm{A}(\mathrm{X})$ are closed subspaces of X.Then $C(A, S) \neq \varnothing$ and $C(A, S) \neq \varnothing$.

Proof. Since the pairs (A, S) and (B, T) satisfy a common property (E.A.). Then there exist sequences $\left\{x_{n}\right\}$ and $\left\{y_{n}\right\}$ in $\mathrm{X}$ such that

$$
\lim _{n \rightarrow \infty} \mathrm{Ax}_{\mathrm{n}}=\lim _{n \rightarrow \infty} \mathrm{Sx}_{\mathrm{n}}=\lim _{n \rightarrow \infty} \mathrm{Ty}_{\mathrm{n}}=\lim _{n \rightarrow \infty} B \mathrm{y}_{\mathrm{n}}=\mathrm{z} .
$$

Assume that $\mathrm{B}(\mathrm{X})$ and $\mathrm{A}(\mathrm{X})$ are closed subspaces of $\mathrm{X}$. Then,

$$
\mathrm{z}=\mathrm{Bu}=\mathrm{Av} \text { for some } \mathrm{u}, \mathrm{v} \in \mathrm{X} \text {. }
$$

If $S v \neq z$, then from (2.1), (2.2) and (2.3), we have

$$
\begin{aligned}
& \int_{0}^{d\left(S v, T y_{n}\right)} \phi(s) d s \leq \alpha \int_{0}^{m\left(v, y_{n}\right)} \phi(s) d s+\beta \\
& \int_{0}^{M\left(v, y_{n}\right)} \phi(s) d s, \text { where } \\
& m\left(v, y_{n}\right)=\mathrm{d}\left(\mathrm{By}_{\mathrm{n}}, \mathrm{Ty}_{\mathrm{n}}\right) \frac{1+d(A v, S v)}{1+d\left(A v, B y_{n}\right)} \text { and } \\
& M\left(v, y_{n}\right)=\max \left\{\mathrm{d}\left(\mathrm{Av}, \mathrm{By} \mathrm{y}_{\mathrm{n}}\right), \mathrm{d}(\mathrm{Av}, \mathrm{Sv}), \mathrm{d}\left(\mathrm{By}_{\mathrm{n}}, \mathrm{Ty}_{\mathrm{n}}\right)\right\},
\end{aligned}
$$


on letting $\mathrm{n} \rightarrow \infty$, we have $\mathrm{Sv}=\mathrm{z}$ and thus

$$
\mathrm{Sv}=\mathrm{Av}=\mathrm{z} \text {. }
$$

again if $\mathrm{Tu} \neq \mathrm{z}$, then from (2.1), (2.3) and (2.4), we get

$\int_{0}^{d(S v, T u)} \phi(s) d s \leq \alpha \int_{0}^{m(v, u)} \phi(s) d s+\int_{0}^{M(v, u)} \phi(s) d s$,

where

$\mathrm{m}(\mathrm{v}, \mathrm{u})=\mathrm{d}(\mathrm{Bu}, \mathrm{Tu}) \frac{1+d(A v, S v)}{1+d(A v, B u)}$ and $\mathrm{M}(\mathrm{v}, \mathrm{u})=\max \{\mathrm{d}(\mathrm{Av}$,

$\mathrm{Bu}), \mathrm{d}(\mathrm{Av}, \mathrm{Sv}), \mathrm{d}(\mathrm{Bu}, \mathrm{Tu})\}$, we get

(2.5) $\mathrm{Tu}=\mathrm{z}=\mathrm{Bu}$.

Hence, from (2.4) and (2.5), it follows that

$\mathrm{C}(\mathrm{A}, \mathrm{S}) \neq \varnothing$ and $\mathrm{C}(\mathrm{A}, \mathrm{S}) \neq \varnothing$.

Theorem 2.6. In addition to hypothesis of proposition (2.5) on $\mathrm{A}, \mathrm{B}, \mathrm{S}$ and $\mathrm{T}$, if both the pairs $(\mathrm{A}, \mathrm{S})$ and $(\mathrm{B}, \mathrm{T})$ are owc on $\mathrm{X}$, then the maps $\mathrm{A}, \mathrm{B}, \mathrm{S}$ and $\mathrm{T}$ have a unique common fixed point in X.

Proof. By Proposition 2.5, C (A, S) $\neq \emptyset$ and C (A, S) $\neq \varnothing$. The rest of the proof runs as that of Theorem 2.2.

Now we give an example in support of Theorem 2.6.

Example 2.7. Let $X=\left[\frac{1}{3}, 1\right)$ with the usual metric. We define mappings $\mathrm{A}, \mathrm{B}, \mathrm{S}$ and $\mathrm{T}$ on $\mathrm{X}$ by

$$
\begin{aligned}
& \mathrm{A}(\mathrm{x})=\left\{\begin{array}{ll}
\frac{1}{2} & \text { if } \frac{1}{3} \leq x<\frac{3}{4} \\
1-\frac{1}{3} x & \text { if } \frac{3}{4} \leq x<1,
\end{array} \quad \mathrm{~B}(\mathrm{x})=\right. \\
& \left\{\frac{1}{2} \quad \text { if } \frac{1}{3} \leq x<\frac{3}{4}\right. \\
& \left\{\frac{1}{2}+\frac{1}{3} x \quad \text { if } \frac{3}{4} \leq x<1,\right. \\
& \mathrm{S}(\mathrm{x})=\mathrm{T}(\mathrm{x})=\left\{\begin{array}{l}
\frac{17}{20} \text { if } \frac{1}{3} \leq x<\frac{3}{4} \\
\frac{3}{4} \quad \text { if } \frac{3}{4} \leq x<1
\end{array}\right.
\end{aligned}
$$

Here we observe that both $\mathrm{B}(\mathrm{X})$ and $\mathrm{A}(\mathrm{X})$ are closed; and neither $\mathrm{T}(\mathrm{X}) \subseteq \mathrm{A}(\mathrm{X})$ and $\mathrm{S}(\mathrm{X}) \subseteq \mathrm{B}(\mathrm{X})$. The inequality (2.1) holds with $\phi(s)=1$ and $\alpha=\frac{1}{3}, \beta=\frac{1}{2}$. The sequence $\left\{\mathrm{x}_{\mathrm{n}}\right\}, \mathrm{x}_{\mathrm{n}}$ $=\frac{3}{4}+\frac{1}{n+5}, \mathrm{n}=1,2,3 \ldots$ is in $\mathrm{X}$ such that $\lim _{n \rightarrow \infty} A \mathrm{Ax}_{\mathrm{n}}=\lim _{n \rightarrow \infty} \mathrm{Sx}_{\mathrm{n}}=$ $\lim _{n \rightarrow \infty} B \mathrm{x}_{\mathrm{n}}=\lim _{n \rightarrow \infty} \mathrm{Tx}_{\mathrm{n}}=\frac{3}{4}$, so that the pairs $(\mathrm{A}, \mathrm{S})$ and $(\mathrm{B}, \mathrm{T})$ satisfy common property (E.A.). Clearly, the pairs (A, S) and (B, T) are owc. Hence, the self-maps A, B, S and T satisfy all the conditions of Theorem 2.6 and $\frac{3}{4}$ is the unique common fixed point of A, B, S and T.

\section{REFERENCES}

[1] M. Aamri and D. El. Moutawakil, Some new common fixed point theorems under strict contractive conditions, J. Math. Anal. Appl., 27(2002),181-188.

[2] M. A. Al-Thagafi, N. Shahzad, Generalized Inonexpansive selfmaps and invariant approximations, Acta Math. Sin.(Engl. Ser.) 24(2008) 867-876.

[3] M. A. Al-Thagafi, N. Shahzad, A note on occasionally weakly compatible maps, Int. J. Math. Anal., 3(2) (2009) 55-58.

[4] I. Altun, D. Turkoglu, B. E. Rhoades, Fixed points of weakly compatible maps satisfying a general contractive condition of integral type, Fixed Point Theory Appl. 2007 (2007) Article ID 17301, 9 pages.

[5] G. V. R. Babu, G. N. Alenmayehu, A common fixed point theorem for weakly contractive mappings satisfying property (E.A.), Appl. Math. E-Notes 10 (2010) 167-174.

[6] G. V. R. Babu, G. N. Alenmayehu, Points of coincidence and common fixed points of a pair of generalized weakly contractive mappings, J. Adv. Res. Pure Math., 2(2) (2010) 89-106.

[7] G. V. R. Babu, G. N. Alenmayehu, Common fixed point theorems for occasionally weakly compatible maps satisfying property (E.A.) using an inequality involving quadratics terms, Applied Mathematics Letters 24(2011) 975-981.

[8] A. Branciari, A fixed point theorem for mappings satisfying a general contractive condition of integral type, Int. J. Math. Math. Sci., 29 (2002) 531-536.

[9] A. Djoudi, A Aliouche, Common fixed point theorems of Gregus type for weakly compatible mappings satisfying contractive conditions of integral type, J. Math. Anal. Appl., 329 (2007) 31-45.

[10] G. Jungck, Common fixed points for non-continuous non-self maps on non-metric spaces, Far East J. Math. Sci., 4(2) (1996), 199-215.

[11] G. Jungck, Compatible mappings and common fixed points, Int. J. Math. Math. Sci., 9(4) (1986), 771-779.

[12] G. Jungck, Commuting mappings and fixed points. Amer. Math. Monthly,83, (1976), 261-263.

[13] G. Jungck, B. E. Rhoades, Fixed points for set-valued functions without continuity, Indian J. Pure Appl. Math., 29(3) (1998) 227-238.

[14] G. Jungck, B. E. Rhoades, Fixed point theorems for occasionally weakly compatible mappings, Fixed Point Theory 7(2006) 286-296.

[15] R. Kannan, Some results on fixed points, Bull. Cal. Math. Soc., 60 (1968), 71-76.

[16] W. Liu, J. Wu, Z. Li, Common fixed points of singlevalued and multi-valued maps, Int. J. Math. Math. Sci. 19 (2005) 3045-3055.

[17] A. Meir, E. Keeler, A theorem on contraction mappings, J. Math. Anal. Appl., 28 (1969) 326-329.

[18] H. K. Pathak, Rosana Rodriguez-Lopez and R. K. Verma,A common fixed point theorem using implicit relation and property (E.A.) in metric spaces, Filomat 21(2) (2007), 211-234.

[19] B. E. Rhoades, Two fixed point theorems for mappings satisfying a general contractive condition of integral type, Int. J. Math. Math. Sci., 63 (2003) 4007-4013.

[20] S. Sessa, On a weak commutativity condition of mappings in fixed point considerations, Publ. Inst. Math., 32 (1982) 149-153.

[21] T. Suzuki, Meir-Keeler contractions of integral type are still Meir-Keeler contractions, Int. J. Math. Math. Sci., 2007 (2007) Article ID 39281, 6 pages.

[22] C. Vetro, On Branciari's theorem for weakly compatible mappings, Applied Mathematics Letters 23 (2010) 700705 .

[23] P. Vijayaraju, B. E. Rhoades, R. Mohanraj, A fixed point theorem for a pair of maps satisfying a general contractive condition of integral type, Int. J. Math. Math. Sci. 15 (2005) 2359-2364. 